\title{
Erratum to: Finite Element Analysis-Based Damage Metric for Airtightness Performance Evaluation of Concrete Tube Structures
}

\author{
Prakash Devkota ${ }^{\oplus a}$, Heung Woon Jang ${ }^{\circledR b}$, Jung-Wuk Hong ${ }^{\circledR c}$, and Joonam Park ${ }^{\circledR d}$ \\ ${ }^{a}$ Dept. of Civil and Environmental Engineering, Wonkwang University, Iksan 54538, Korea \\ ${ }^{b}$ Dept. of Civil and Environmental Engineering, Korea Advanced Institute of Science and Technology, Daejeon 34141, Korea \\ 'Member, Dept. of Civil and Environmental Engineering, Korea Advanced Institute of Science and Technology, Daejeon 34141, Korea \\ ${ }^{d}$ Member, Dept. of Civil and Environmental Engineering, Wonkwang University, Iksan 54538, Korea
}

\section{Erratum to: KSCE Journal of Civil Engineering (2021) 25(4):1385-1398}

$10.1007 / \mathrm{s} 12205-021-1007-8$

This erratum is published to notify a correction in the acknowledgements. See the corrected version below:

\section{Errata:}

The original version of this article:

This research was funded by Wonkwang University in 2017.

\section{Was altered as:}

This research was funded by Wonkwang University in 2019. 